\title{
Mass Tourism and Air Transport, an Inevitable Relationship: The Case of Canary Islands
}

\author{
Victor S. Pescador \\ Art City and Territory Department, University of Las Palmas de Gran Canaria, Las Palmas de Gran Canaria 35001, Spain
}

\begin{abstract}
The tourist industry, as global mass phenomenon, is inextricably linked to the evolution of air transport systems and air carriers, in turn, depends on tourism to ensure stability in routes and prices. Therefore, both sectors must face the new challenges together, the transport industry is heading a problem of energy and cost overruns, that inevitably will affect tourism in the short term. The first energy crisis that they are starting to live, has been mitigated by changes in three parameters: (1) the international regulation of commercial aviation; (2) the connectivity and business (birth of low cost companies) models; and (3) the new policies for climate change and gas emission. So far, the rapid growth of the tourist industry has being held on a fast and cheap access to transport energy resources based on the false belief of unlimited access to energy. The article is a review of the state of the art, and the research papers published on air transportation, relating to tourism and the emergence of low cost airlines, in order to give a global vision for the decision makers of mass destinations, as it is the case of the Canary Islands that we will use as a reference.
\end{abstract}

Key words: Air transport, low cost, energy cost, island tourist destinations, sustainability, kerosene price, oil peak.

\section{Introduction}

The increase of the oil prices, the investments made in the field of aviation safety from the terrorist attacks of $9 / 11$, the use of new technologies to purchase online and inquiry of air services, the Open Skies Treaty and the global economic crisis, were all factors that have pushed airlines to processes of fusion, disappearance or transformation, irrespective of its way of operating: regular, charter or LCC (low cost company). These changes in the market has brought with it new management models, depending on the type of company, on the basis of cost-cutting, reducing the number of operations and the closure of unprofitable lines in some cases, and transforming the marketing of the product with supplementary income payments for services, and kilo transported in others. The continuous increase of primary energy has direct reflection on air transported prices transferred to tourists, making it necessary to reduce costs at destination in order to remain competitive in the

Corresponding author: Victor S. Pescador, Ph.D., architect, research field: sustainable tourism. tourist package. This causes short term loss of the quality of the offer, with the consequent deterioration in infrastructure, following the pattern of the Gauss campaign with a peak and a fast decline of the tourist destination.

Although the present work can move globally, it is contextualized in the Canary Islands as a relevant tourist destination, putting data that can help the understanding of the problems posed.

\section{The Energy Scene in Air Transport}

The air transport is one of the sectors that has most suffered the structural changes that are taking place in the global economy since the oil price crisis in 2006/2008, during which the barrel climbed to high of \$142. A standard plane consumes an average of 3.51 of kerosene per $100 \mathrm{~km}$ and seat offered on long-haul routes, such as the case of the Canary Islands, from center European markets issuers [1].

A total of 47 of the major European airlines operate in the five large island airports, with 166 air connections throughout the year without tourist seasonality due to the climate conditions. Making a 
basic study of flying costs in relation to competitors, and based exclusively on the costs per unit of displacement in main issuing markets, reflected in Fig. 1, you obtain an average cost per passenger per $100 \mathrm{~km}$ distance of $€ 11.92$ for the Canary Islands destination, $€ 12.70$ for destinations in Spain mainland, $€ 14.13$ for Croatian coast and $€ 10.12$ for Turkey (all Canary Island competitors).

The difference of price per unit between destinations is not very significant which reflects clearly the weight of the fuel front overhead cost. However, the distance is substantially greater on flights to Canary Islands, representing a $40 \%$ increase in the cost of transportation with respect to its competitors, and obviously, both lines will not remain parallel as the oil prices increases. The influence of transport spends on the average expenditure per tourist and day (Table 1), is more than evident. Every year the origin spending increases, the destination spending decreases, as well as the cost per day of overnight hotel stays. This means that the cost of the tourist package has grown in relation to transport without having the demand the ability for rising the spending, therefore, the differential cost is taken on destination. If the average expenditure per tourist and day is $€ 128.28$ with a 9.9 nights stay, and the transport cost is $€ 46.05$ per tourist and day, is immediate that $37 \%$ of the total is destined for air transport (Table 2), and therefore, any variation in fuel prices will affect directly on this, with an important weight on total expenditures. It is essential

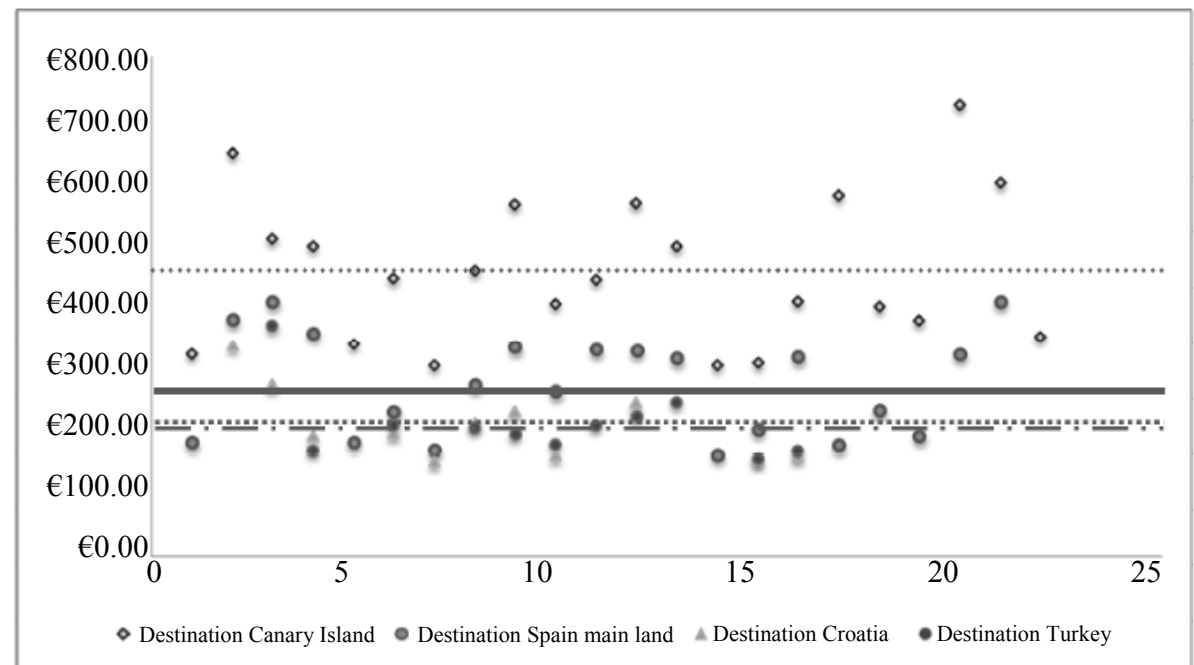

Fig. 1 Transport costs according to destination.

Table 1 Transport costs according to destination [2].

\begin{tabular}{|c|c|c|c|c|c|c|}
\hline \multicolumn{7}{|c|}{ Average total expenditure per person and day (unit in Euros) } \\
\hline & 2009 & 2010 & 2011 & 2012 & 2013 & 2014 \\
\hline Total expenditure & 113.23 & 117.13 & 118.71 & 124.11 & 129.64 & 128.28 \\
\hline In origin & 73.89 & 79.07 & 81.40 & 86.83 & 101.81 & 100.32 \\
\hline In Gran Canaria & 39.34 & 38.05 & 37.3 & 37.28 & 27.84 & 27.96 \\
\hline Extra accommodation & 5.36 & 5.29 & 3.06 & 3.98 & 2.94 & 3.06 \\
\hline Public transport & 2.43 & 2.02 & 1.96 & 1.76 & 0.89 & 0.83 \\
\hline Car rental & 1.42 & 1.82 & 1.13 & 1.10 & 1.86 & 1.80 \\
\hline Food and shopping & 4.48 & 6.35 & 6.32 & 7.08 & 4.04 & 4.22 \\
\hline Restaurants & 10.21 & 8.60 & 9.18 & 8.88 & 5.58 & 5.98 \\
\hline Souvenirs & 4.32 & 6.73 & 6.98 & 7.50 & 6.34 & 6.29 \\
\hline Leisure & 7.11 & 5.30 & 5.19 & 5.03 & 4.53 & 4.33 \\
\hline Other concepts & 4.02 & 1.94 & 3.50 & 1.96 & 1.66 & 1.44 \\
\hline
\end{tabular}


Table 2 Origin expenditure distribution.

\begin{tabular}{ll}
\hline Spending & Percentage (\%) \\
\hline Accommodation & 27 \\
Air transport & 37 \\
Tourist package & 6 \\
Restaurants & 14 \\
Leisure & 16 \\
\hline
\end{tabular}

then to assess the evolution of the energy prices in the future as a key indicator of competitiveness in the economic development of the destination.

The evolution of kerosene (airplane fuel), has been linked to oil prices as a primary energy source. The price of kerosene reaches its peak in 2008 (American banking crisis and collapse of Lehman Brothers). This first energy crisis has been drawn in part by the more efficient new management model of the LCC, and partly due to the liberalization of Open Skies Treaty (as you will see later), which seems to have stabilized and even decreased the final bid prices. However, looking at the evolution of the average crude oil prices, (Fig. 2), since the 1980s, the upward trend is continuing pushing the kerosene prices up. In the last year, we have seen a sharp decline in oil prices, which has a straightforward explanation of the already exposed, and that it will probably repeat it in the medium term. Rising oil prices in origin has meant that other alternative energy sources or fossil fuels, more expensive to process, become competitive in economic terms, such as fracking or tar sands. This circumstance has consequences that the decrease on cheap oil consumption, the reduction of exports, and therefore, the OPEC (Organization of Petroleum Exporting Countries) incomes. In order to regain market share, the only possible way to be competitive again is reducing prices, stimulating again the market. This circumstance, in the medium term, it would stress the oil resource, and in the coming years, it will generate a saw-tooth graphic that manifest the ups and downs of the barrel prices in origin trying to keep on the market.

The evolution of primary energy prices by the curves of the decline of oil production, according to the theory of the Hubbert peak, shows a scenario of reduction of the amount of primary energy, and a rise of prices due to the increasingly complicated extraction of the new sources, which leads to the raise of energy prices in general, and inevitably the kerosene in particular. The production in the area of the Middle East, it would have reached its "peak" point at the end of the last decade and the beginning of the present, the maximum peak of all reserves has been reached in the year 2010 .

Therefore, they are faced with a dizzying scenario for the next 30 years, of a progressive increase of the

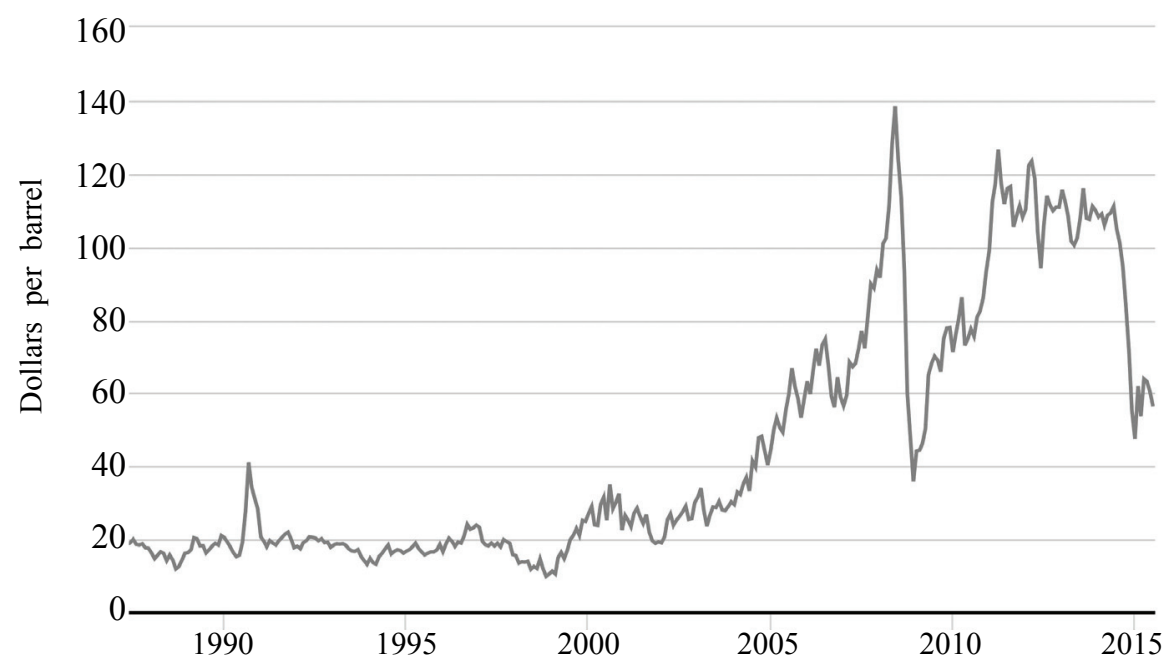

Fig. 2 Evolution of the oil barrel price.

Source: the US Federal Reserve Bank. 
fuel prices which will affect the cost of the airlift. Also, global energy demand is growing at a considerable rate of 5\% annually. And according to predictions from the IEA (International Energy Agency), ${ }^{1}$ it will increase more to one-third of the current in the year 2035, by the higher energy needs of developing countries. By then, it is expected that the global contribution of fossil primary energy would be set at $75 \%$ compared to today's $81 \%$. The energy demand for transport is expected to increase from 87 million barrels per day in 2011 to 99 million barrels per day in the year 2035. However, the offer forecasts moves on an opposite scenario, with a stable production in the coming years to start a gradual descent to the 68 million barrels in 2035, expecting to cover the differential with alternative sources that, by the moment, are not available to the aviation sector.

The direct impact in commercial aviation and tourism that causes the rise of oil prices is noted by following graph in Fig. 3. The data from Canary Islands, reflects the number of tourists received by the Islands in the period 2000 2012, and during the years 2008, 2009 and 2010, can be seen a decrease in the number of arrivals in parallel to the rise of fuel prices, recovering artificially in the years 2011 and 2012 by the irruption of the so-called Arab spring in competing countries of North Africa and continuing with an upward trend due to the lower oil prices.

\section{Open Skies Policy and Expansion of Low Cost Companies}

To understand how the airline industry is being able to sort the beginnings of this energy crisis, and in addition, propel its growth in the midst of a global economic slowdown, it is necessary to know two fundamental facts ranging from hand, the Open Skies Treaty of the EU and the emergence of a new business model - the low cost companies.

The Open Skies Treaty of the EU which was

\footnotetext{
${ }^{1}$ Information from several World Energy Outlook reports on
} the official website of IEA (http://www.iea.org). established in Helsinki in 1992 aims to liberalize the air space control that passes reside in each of the states parties, to be regulated by European control centers, ending bilateral agreements between countries in terms of air traffic and protectionism of national flag companies, with free competition enabling more modest companies to operate between countries at lower cost and also in local routes, although the undoubtedly impetus that has been in the air transport market, still leaves some doubts about its administration, far from the U.S., due to the large number of control centers that translates into the needs of more resources and a higher cost.

The original low cost model business was born in United States from the Southwest Airlines Company, targeting transport routes within the State of Texas operating in secondary airports with the slogan fly is fun, this LCC air model moved to Europe in 1995 through Ryanair, spreading up to 95 companies existing today, which are responsible for approximately 650 million passengers, $24 \%$ of the total, with over 6 million flights, favoring the opening turn of more than 1,200 new routes in Europe since its birth by communicating secondary airports, today, controls almost the $50 \%$ of European airspace.

Fig. 4 shows the evolution and distribution of air transport since the 1990s and clearly reflects the influence of the two exposed events. The rapid initial growth from 1995 that occurs in all companies, is due to the opening of the European airspace, while the LCC were born under cover of the new regulation by copying the American model. From the year 2000 until 2008, 13 million tourists pass to travel in Europe on LCC, with a decrease in the traditional companies of 3 million passengers, so there was not a significant shift toward the LCC, rather the new low cost management model enabled the entry into the market of 10 million new tourists from lower economic resources, that otherwise not have been able to travel. Again in 2008, the economic crisis and the rise of the oil prices paralyzed the market that still does not give signs of recovery, and opens the debate of the possible market saturation. 


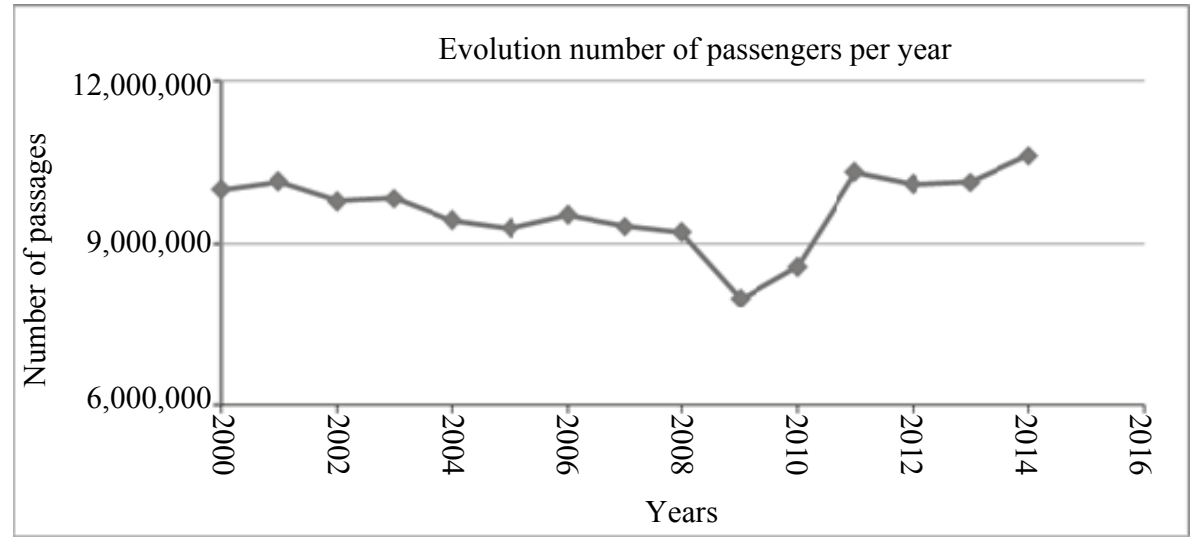

Fig. 3 Evolution of number of passengers per year.

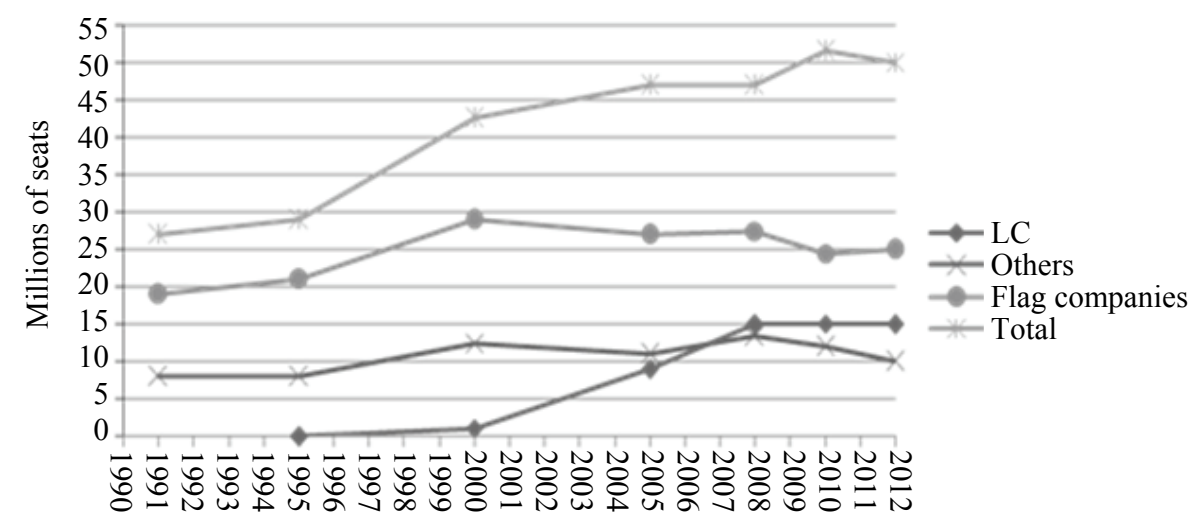

Fig. 4 Intra-European air transport [3].

The low cost airlines business model is based essentially on three pillars which have their repercussions on the tourist market:

- an efficient management control of expenditure;

- point to point flights in short distances;

- local governments aid policies.

(1) Costs management should be paid attention. On one hand, the airports have to adapt to the requirements of companies in terms of capacity, cost (fee reduction) and functional requirements (minimum time stop and hitch 20/25 min), fast check-in without flight connections, good transportation connectivity and good commercial services. Also, the choice of underused second line airports allows them to a more efficient exploitation under their control. Competition between airports and local governments leads to the continuous change of airport on the basis of the best offer.

On the other hand, the expansion of the airplanes capacity to reduce the cost per passenger (the average Ryanair's capacity has risen since 2004, when it operated with the Bae 146 of 110 seats, to the currently 189-seat B737), will imply future routes connected with stopovers, which inevitably will bring up a drop in the frequency of flights. If this is the saving strategy undertaken by the LCC, you must adapt to them and take them into account when designing the tourism strategies [4];

(2) The market segment of this business model is the transportation of short stay family visit, students and city and coastal tourism. This paper focuses only on tourism. Its radius of action, therefore, focuses on short journeys between cities with connection point to point, and using secondary airports. However, with the Open Skies Treaty of the EU, and the extension to Morocco and North Africa, the range has increased considerably to expand the business to routes that 
were never thought it could be part of this model, Canary Islands, despite of their remoteness, in 2012 was the third community in LCC passengers receiving 6.2 million (61.4\%), mostly from United Kingdom and Germany, experiencing a growth of $24 \%$ over the previous year;

(3) Under the expectation of a considerable increase in passengers on direct flights without stopovers and competitive prices, local governments are willing to ensure the requirements of the companies both by investment in airport facilities and by promoting policies that include indirect economic aid. From the Canary Islands-Morocco tourist competition point of view, the open skies agreements between EU and the Kingdom of Morocco do not prohibit state aids to companies, under the guise of initially ensuring the subsistence of some local companies that otherwise would disappear. With this argument, it is justified the granting of these aids contrary to the Treaty of Rome and the laws of free competence of the EU. This agreement has enabled Morocco to enhance from 4.3 million tourists in 2000 to 10 million in 2010 , expecting growth up to 20 million by 2020 . With these conditions, Ryanair has set up 42 new routes with Morocco, which reveals the existence of a tourist market clearly in expansion. The increase in number of operations and flights in Morocco has been rapid since 2004 until the emergence of the so-called Arab spring in 2009, being the LCC responsible of the $87 \%$ of the growth. Moroccan air lines are being doubly benefited by Open Skies Treaty with Europe and United States, establishing a hub with Africa for both continents in Casablanca [5], which guarantees a stable and continuous air traffic which favors the country's tourism development.

In general terms, the irruption of the LCC has contributed to the increase of the tourist market, now well, public subsidies received and the decrease of airport costs, leaves out the market - the traditional companies that are forced to close the less profitable routes by the lack of competitiveness. This trend, although is initially positive to increase the tourist attraction, in the long run, causes a direct dependence on monopolistic companies who also make market decisions in very short time, abandoning the destinations without reaction time. In Canary Islands, this process is already underway, the number of regular routes with the Spanish main land, has been drastically reduced in recent years as a result of the arrival of these companies, which offer seats of around $€ 0.10$ per $\mathrm{km}$, almost half than the traditional ones (it is important to know that the second value in defining the quality of an airline company is the price). This increase in the number and frequency of routes, and the decline in prices had brought with it a change in trends in the tourist market, and the profile of tourists, traditionally a unique holiday period, towards multiple outputs per year, which reduces the average stay period and the expenditure at destination. From the point of view of the market at a current panorama of transport handed out to $50 \%$ between traditional companies and low cost, it is essential to know both passenger profiles, based on an input-output economic impact analysis that allows a better adaptation to the changes by the destinations [6]. From the data published in the tourism expenditure inquest [7] by the Institute of Tourism Studies (Tables 3-5), a distinction is made between tourists arrived in Spain by LCC or traditional.

According to these data, you can create a profile for each type of company, LCC preferences correspond to young people and pensioners, with low incomes or

Table 3 Tourists arrived in Spain by plane, age and company [7].

\begin{tabular}{|c|c|c|c|c|c|}
\hline \multicolumn{6}{|c|}{ Percentage over total air lines companies (2012) (\%) } \\
\hline & $<15$ years old & 15 24 years old & 25 44 years old & $45 \sim 64$ years old & $>64$ years old \\
\hline Low cost companies & 5.00 & 13.00 & 42.50 & 31.60 & 8.00 \\
\hline Traditional companies & 4.50 & 11.15 & 46.80 & 30.60 & 6.70 \\
\hline
\end{tabular}


Table 4 Tourists arrived in Spain by plane, income and company [7].

\begin{tabular}{llllll}
\hline \multicolumn{2}{l}{ Percentage over total by income level (2012) $(\%)$} & & & \\
\hline & Low & Med/low & Medium & Med/high & High \\
\hline Low cost companies & 70.40 & 72.70 & 63.60 & 56.20 & 54.10 \\
Traditional companies & 29.60 & 27.30 & 36.40 & 43.80 & 45.90 \\
\hline
\end{tabular}

Table 5 Average expenditure per tourist reached Spain by plane and company [7].

\begin{tabular}{llllll}
\hline \multicolumn{6}{l}{ Average expenditure over air lines companies (2012) (unit in Euros) } \\
\hline
\end{tabular}

Table 6 Average expenditure per tourist according to the type of company (unit in Euros) [7].

\begin{tabular}{lllllllll}
\hline & 2004 & 2005 & 2006 & 2007 & 2008 & 2009 & 2010 & 2011 \\
\hline Traditional & 973 & 1,018 & 932 & 967 & 967 & 1,010 & 1,041 & 1,060 \\
LCC & 854 & 765 & 794 & 806 & 780 & 806 & 821 & 849 \\
Variatión (\%) & -14 & -33 & -16 & -20 & -24 & -25 & -27 & -25 \\
\hline
\end{tabular}

middle low mostly, and that made less spending on destination. On the other hand, traditional companies' users are in the age group between 25 and 44 years old, with medium high and high incomes, and capable of more spending. If we transfer the data to an expenditure per tourist table in recent years (Table 6), you have a $25 \%$ difference in favor of the traditional, even with a $30 \%$ saved cost on transport tickets by the LCC users. This less demand in consumption by the low cost airlines tourist translates into a reduction of GDP (gross domestic product) and hence a decrease in jobs in destination.

\section{Conclusions}

As the world energy market is coming up, it can be concluded that air transport costs will increase gradually in the coming years, driven by the rise in the prices of primary energy, focusing on sun and sand mass destinations, which moved the greater number of tourists with very cheap all-inclusive packages. As transport costs increase, therefore, tourist packages prices rise, then a gradual decline in number of tourists will occur. The aeronautical industry tries to find new alternative substitute oil sources compatible with current and future technologies, such as lignocellulosic materials research, the hydrogenation of fats or the production of alcohols, in order to shorten the deadlines for its commercial availability. However, these ongoing technologies are today far from being applied on commercial aviation.

The differential energy cost is not assumable by the tourist industry, which has made a remarkable effort in the last decade to improve the management of its resources, and the monetary union no longer allows the countries to maintain the competitiveness by devaluating the currency. As soon as an alternative energy source it is not found, one of the ways whereby the industry opted to lower the cost/passenger is expanding the capacity of the aircraft, which is already happening, and that will require the adaptation of the airport facilities for bigger aircraft. The main manufacturers have been long working on two fronts: on one hand, the design of aircraft operating at high altitudes which reduces consumption and significantly reduces the time travel (stratoliner); and on the other, the increase in load capacity to decrease the cost per passenger and miles (the NASA (National Aeronautics and Space Administration) "double bubble" D8 or the new airbus).

The irruption of the LCC may be good at first stay for tourism, but there are two nuances to consider: First, the monopolization in certain destinations by companies may result in higher prices and a reduction in flights in the medium term, decreasing connectivity 
in less profitable routes, by pushing out of the market the less efficient companies, creating instability in tourist markets; And secondly, the number of passengers that appears in recent years by offering low prices, belongs to a segment of minor economic resource, and as the price of fuels increases, as you have already seen, and the cost is transferred to the consumer, they will be disappearing from the demand. So, the supply will suffer and the number of routes will decrease missing the basic connectivity for the tourist market, and destinations will have to assume a percentage of loss of tourists with lower purchasing power.

Having a market split between low cost airlines and traditional with different client profiles in terms of spending capacity, seems logical to maintain at least the parity on transport between them at destination; On the other hand, a higher cost of transport can be reduced in two ways: increasing the load capacity or the period of stay returning to a more traditional vacation model. If the first solution depends on the commercial aviation, the second is up to destinations, both are doomed to be understood. Destinations must be attentive to the changes that can produce in commercial airline strategies, and decide whether to get involved, and how, in commercial air transport operations, will therefore need to be aware and to quantify the weight that air transport has in each destination. Advances in transportation and management models, have brought with them that tourist demands change rapidly, so tourist destinations are going to require a greater dynamism and adaptability to move in an unpredictable economic environment.

\section{References}

[1] Salvador, C., trans. 2010. Definition of Indicators and Sustainability Models to Evaluate the Environmental Impact of Air Transport. Report of OBSA (Observatory of Sustainability of Aviation) Canary Islands.

[2] ISTAC (Instituto Canario de Estadistica). 2015. "EGT/Series Trimestrales de Gasto Turístico. Islas de Canarias. 2009-2015.” ISTAC. Accessed April 12, 2016. http://www.gobiernodecanarias.org/istac/jaxi-istac/menu. do?uripub=urn:uuid:8429abec-2b5d-465a-a777-a5f2e32 a75bd. (in Spanish)

[3] OAG. 2013. "Traffic Analyser." OAG. Accessed April 12, 2016. http://www.oag.com/analytics/traffic-analyser.

[4] Dobruszkes, F. 2013. "The Geography of European Low-Cost Airline Networks: A Contemporary Analysis." Journal of Transport Geography 28: 75-88.

[5] Dobruszkes, F. 2013. "Aviation Liberalization as a Means to Promote International Tourism: The EU-Morocco Case." Journal of Air Transport Management 29: 23-34.

[6] Puertas, M. R. 2012, "Impacto Económico del Gasto Turístico: Compañías de Bajo Coste versus Tradicionales." Revista de Economía Mundial 32: 51-71. (in Spanish)

[7] IET (Instituto de Estudios Turísticos). 2013. "Estadísticas Turísticas." IET. Accessed April 12, 2016. http://estadisticas.tourspain.es/es-ES/turismobase/Paginas /default.aspx. (in Spanish) 